\title{
A golden ratio for foramen magnum: an anatomical pilot study
}

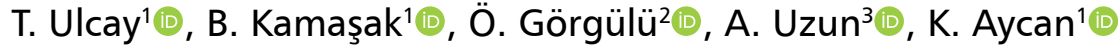 \\ ${ }^{1}$ Department of Anatomy, Faculty of Medicine, Kırşehir Ahi Evran University, Kırşehir, Turkey \\ 2Department of Biostatistics, Faculty of Medicine, Kırşehir Ahi Evran University, Kırşehir, Turkey \\ ${ }^{3}$ Department of Anatomy, Faculty of Medicine, Ondokuz Mayıs University, Samsun, Turkey
}

[Received: 4 January 2021; Accepted: 27 January 2021; Early publication date: 23 February 2021]

Background: The foramen magnum (FM) is an important landmark because of its close relationship to key structures such as the brainstem and spinal cord, an extension of the medulla oblongata. Because of the similarity in their shape, the existence of a relationship between cranial length and anteroposterior diameter of the FM, and between cranial width and transverse diameter of the FM may reveal the magnificent harmony of the skull and FM. Based on this idea, we investigated the existence of this harmony in skulls that we used in our study.

Materials and methods: In this study, 60 adult dry skulls belonging to the Turkish population were examined. The anteroposterior and transverse diameters of the foramen magnum and the length and width of the skull were measured. Measurements were made directly on the skull using a digital sliding calliper. New indices and ratios were applied with those measurements.

Results: Our study suggests that FM width and FM length could be estimated by using the cranial length and cranial width measurements in the skull by accepting the mean of these coefficients (4.62) as the golden ratio. The average of the coefficients of cranial width to FM width ratio (4.62 \pm 0.35 [95\% Cl: 4.52-4.70]) and the average of the coefficients of cranial length to the FM length ratio (4.62 \pm 0.50 [95\% Cl: 4.49-4.76]) were found to be equal to each other. In order to check the accuracy of this hypothesis, FM width and FM lengths were estimated with the help of new equations.

Conclusions: In the present study, the ratio between the anteroposterior and transverse diameters of both FM and the cranium was estimated at 4.62, indicating a magnificent harmony between cranial and subcranial structures. With this ratio, it is easy to estimate FM's size based on simple cranial measurements. (Folia Morphol 2022; 81, 1: 220-226)

Key words: anthropometry, foramen magnum, occipital bone, skull base

\section{INTRODUCTION}

The human occipital bone, like that of most other mammals, is ontogenetically and functionally unique when compared to other bones of the cranium. It is one of the first bones of the skull to develop and consists anatomically of four parts surrounding the

Address for correspondence: Assist. Prof. Dr. T. Ulcay, Department of Anatomy, Faculty of Medicine, Kırşehir Ahi Evran University, Kırşehir, Turkey, tel: +90 50556215 47, e-mail: tufanulcay@gmail.com

This article is available in open access under Creative Common Attribution-Non-Commercial-No Derivatives 4.0 International (CC BY-NC-ND 4.0) license, allowing to download articles and share them with others as long as they credit the authors and the publisher, but without permission to change them in any way or use them commercially. 
foramen magnum (FM): the basilar, squamous, and two condylar parts [3]. The FM is an important landmark because of its close relationship to key structures such as the brainstem and spinal cord, an extension of the medulla oblongata. The FM also transmits the vertebral and spinal arteries, tectorial membranes, and alar ligaments. Thus, the FM is of particular interest to clinicians, such as radiologists, neurosurgeons, or skull-base surgeons $[5,10]$. The anterior border of the FM is formed by the basilar process of the occipital bone, the lateral borders by the left and right ex-occipitals, and the posterior border is formed by the supra-occipital part of the occipital bone [7].

Anatomical knowledge of FM is important for understanding several pathologic conditions as well as for planning surgical procedures [13]. For instance, the length and breadth of the FM is clinically relevant in patients with achondroplasia; the cervicomedullary junction may be compressed as a result of marked FM stenosis, resulting in neurologic manifestations [21]. In addition, the knowledge of the dimensions and shape of the FM has important clinical implications in the prognosis and treatment of various neurological pathologies like Arnold Chiari syndrome, and posterior cranial fossa lesions $[23,26]$. As in FM meningioma resection, in transcondylar surgical approach to FM, anatomical features of the FM and variations in condylar resections to expose FM have been taken into consideration in various studies $[8,24]$. Wanebo et al. [27] stated that longer FM anteroposterior diameters permitted greater contralateral surgical exposure for condylar resection. Thus, understanding of the anatomical features, dimensions, shape types, variations and morphometry of the FM is essential for accurate diagnosis and treatment of these pathologies.

Also variations of the shape of FM have got diagnostic, clinical and radiological importance. The morphological variants of the shapes of FM: round, shape, egg, tetragonal, oval, irregular, hexagonal and pentagonal shapes $[5,9]$.

Additionally, many authors have reported the usefulness of the FM in gender determination $[6,11$, $16,18]$. In 1982, Teixeira [25] revealed the basic osteometric data of the two main diameters of the human FM regarding gender, age, height, ethnic origin and secular disposition.

Despite its particular clinical importance, only a few anatomical reports on FM are available in the literature. These reports are generally on measurement of the current size of FM $[10,21,23]$, determination of its shape [5, 23], gender differences [7, 11, 25], ethnic differences $[6,18]$, dimensions in other mammals [14] and relationship to the intra-cranial volume [1].

However, the relationship between the FM and cranial dimensions were not fully analysed so far. The similarity in shape between the skull and FM may suggest a relationship between cranial length and anteroposterior diameter of FM and between cranial width and transverse diameter of FM. Those relations may reveal the magnificent harmony of the skull and FM. Based on this idea, we investigated this harmony's existence in 60 skulls that we used in our study. In other words, our study aims to investigate the possible relationship between cranial length and the anteroposterior diameter of the FM (in the sagittal plane) and between the cranial width and the transverse diameter of the FM (in the coronal plane).

\section{MATERIALS AND METHODS}

In the present study, 60 dry skulls of human adults from the Turkish population were examined. The exact age and sex of the skulls have not been determined. The different shapes of the FM were macroscopically noted and classified as two semicircle, oval, round, egg, tetragonal, pentagonal, hexagonal and irregular shapes. The shapes were determined after the discussion with team of three members in order to avoid observational bias. The number and incidence of each type in the studied skull was registered and tabulated. The anteroposterior and transverse diameters of the FM were measured using digital sliding callipers (Mitutoyo) with $0.1 \mathrm{~mm}$ precision. The anteroposterior diameter was measured from the end of the anterior border (basion) to the end of the posterior border (opisthion). The transverse diameter was measured from the point of maximum concave on the right edge to the maximum concave on the left edge (Fig. 1A).

The length of the skull was assumed as the distance between the glabella (g) and opisthocranion (g-op). The skull width was measured between the two most remote points (eurion-eurion) located on the right and the left side of the skull (eu-eu) (Fig. 1B).

In the present study, new indices were determined from measurements of the FM and skull. Measurements in the coronal and sagittal planes were used to determine these indices. While the measurements in the coronal plane were used to calculate the foramen magnum width-cranial width (FMW-CW) index, the measurements in the sagittal plane were used to 


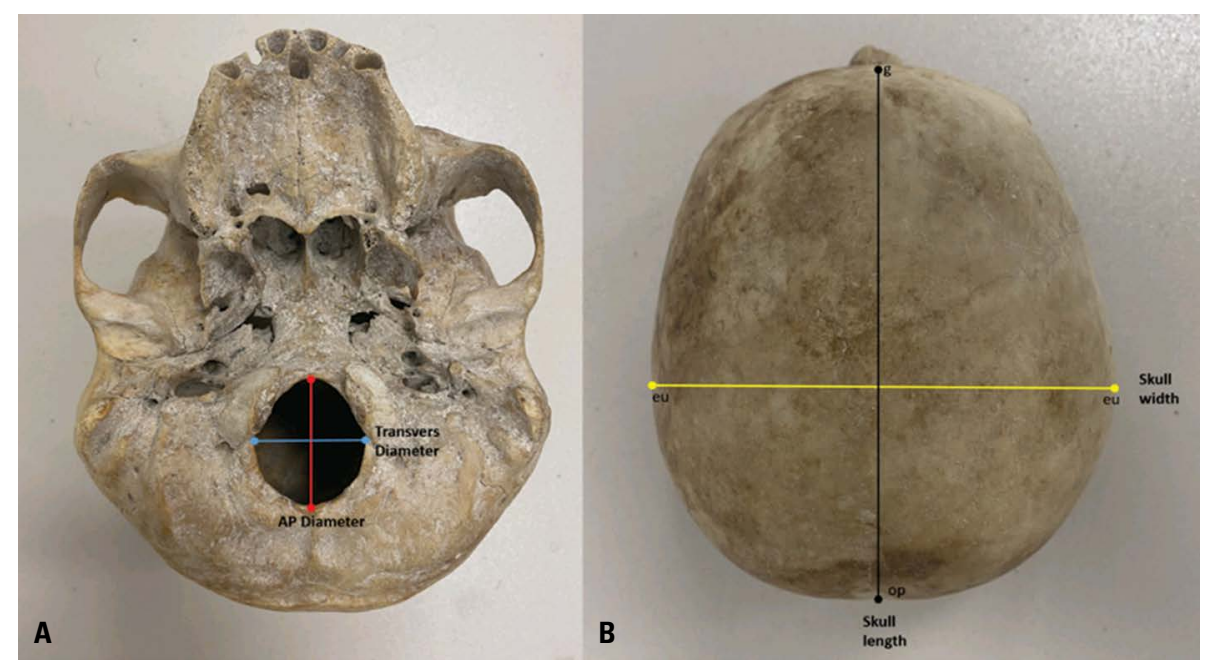

Figure 1. A, B. Antero-posterior (AP) and transverse diameters of foramen magnum and skull measurements.

calculate the foramen magnum length-cranial length (FML-CL) index.

$$
\begin{array}{ll}
F M W-C W \text { index }=\frac{F M W}{C W} \times 100 & \text { (equation-1) } \\
F M L-C L \text { index }=\frac{F M L}{C L} \times 100 & \text { (equation-2) }
\end{array}
$$

When calculating the cranial index (cranial width/ cranial length $\times 100)$ and $F M$ index (FM width/FM length $\times 100$ ), the ratio of width measurements to length measurements is always taken. From this point of view, it was thought that the ratio of equation-1 (width index) and equation-2 (length index) to each other might be an indicator of the magnificent harmony in the skull.

\section{Statistical analysis}

Statistical analysis of the study data was performed using SPSS version 21.0 software for Windows (IBM SPSS Statistics for Windows, Version 21.0. Armonk, NY: IBM Corp., USA). Normality assumption was tested using Kolmogorov-Smirnov and Shapiro-Wilk tests. The assumption of homogeneity of variances was tested with the Levene's test. Data was expressed as mean \pm standard deviation (SD) and number ( $\mathrm{n}$ ). Independent t-test was used to the comparison of the groups in the study. In all statistical tests, $p$ value $<0.05$ was considered to indicate accepted to be statistically significant.

\section{RESULTS}

When we compared the width index (equation-1) and the length index (equation-2), those two indices, surprisingly, were approximately equal (1.01).
Within the scope of this equation, as a result of the measurements we made from 60 human skulls, the average of the coefficients of cranial width to FM width ratio $(4.62 \pm 0.35$ [95\% confidence interval: $4.52-4.70])$ and the average of the coefficients of cranial length to FM length ratio (4.62 \pm 0.50 [95\% confidence interval: 4.49-4.76]) were found to be equal to each other. The relationship between these coefficients calculated in 60 skulls was found to be statistically insignificant $(p>0.05)$ (Table 1$)$.

In our study, it was suggested that FM width $(28.14 \pm 1.77 \mathrm{~mm})$ and FM length $(35.81 \pm 7.56 \mathrm{~mm})$ can be estimated by using the cranial length $(162.45 \pm$ $\pm 6.20 \mathrm{~mm})$ and cranial width $(129.45 \pm 4.99 \mathrm{~mm})$ measurements in the skull by accepting the mean of these coefficients (4.62) as the golden ratio. In order to check the accuracy of this hypothesis, FM width and FM lengths were estimated with the help of equation-3 and equation-4.

$$
\begin{array}{ll}
F M \text { Width }=\frac{\text { Cranial Width }}{4.62} & \text { (equation-3) } \\
F M \text { Lenght }=\frac{\text { Cranial Lenght }}{4.62} \quad \text { (equation-4) }
\end{array}
$$

There was no statistically significant difference between the measured (observed values) FM width and estimated FM width $(p>0.05)$. Similarly, there was no statistically significant difference between the measured (observed values) FM length and estimated FM length values $(p>0.05)$ (Table 1).

Eight different shapes were observed for the FM. Type, quantity and frequency of these are shown in Figure 2 and Table 2. In our study, the occipital condyle was not observed to protrude into the FM in any of the skulls. 
Table 1. Descriptive statistics of variables and group comparisons

\begin{tabular}{lccc}
\hline & Mean \pm SD & 95\% Cl (lower-upper) & P value \\
\hline Cranial width & $129.45 \pm 4.99$ & $117.0-138.0$ & - \\
Cranial length & $162.45 \pm 6.20$ & $151.0-178.5$ & 0.889 \\
Cranial width/FM width & $4.62 \pm 0.35$ & $4.52-4.70$ & \\
Cranial length/FM length & $4.62 \pm 0.50$ & $4.49-4.76$ & 0.640 \\
FM width (observed values) & $28.14 \pm 1.77$ & $27.68-28.60$ & 0.513 \\
FM width (prediction values) & $28.01 \pm 1.07$ & $27.74-28.29$ & $33.85-37.76$ \\
FM length (observed values) & $35.81 \pm 7.56$ & $34.81-35.50$ & \\
FM length (prediction values) & $35.16 \pm 1.34$ & & \\
\hline
\end{tabular}

$\mathrm{Cl}$ — confidence interval; $\mathrm{FM}$ — foramen magnum; SD — standard deviation
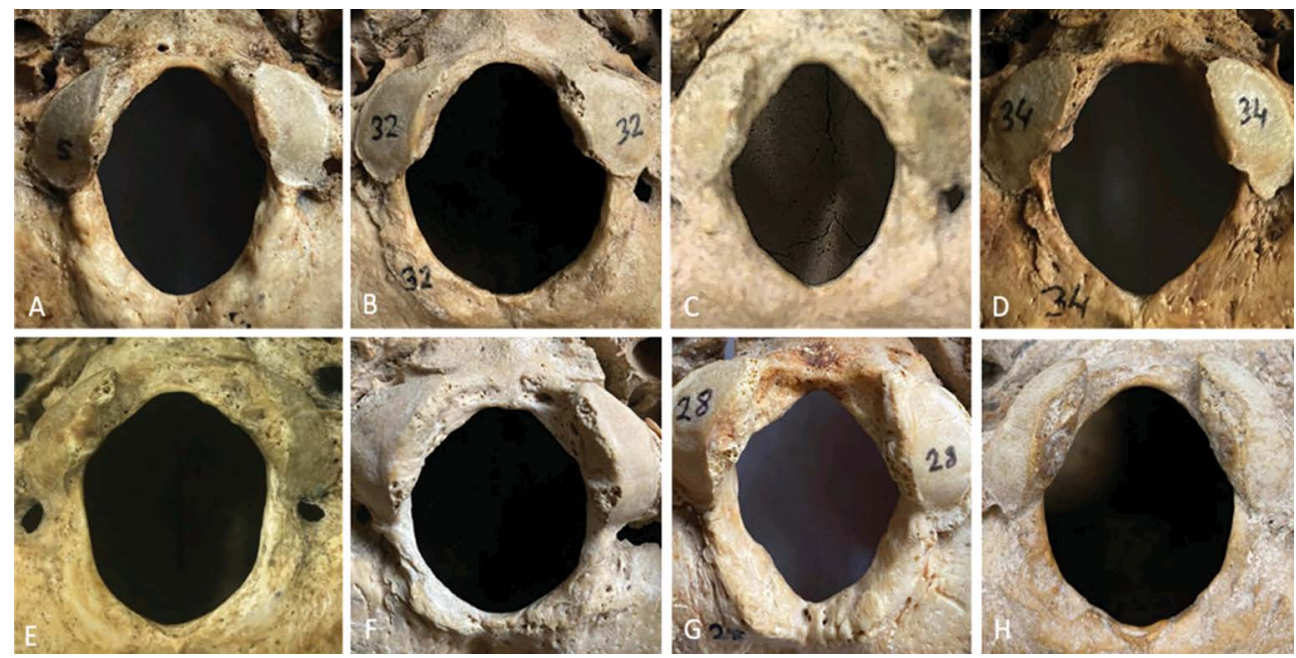

Figure 2. Different shape types of the foramen magnum; A. Oval; B. The hole formed by the combination of two semicircles; C. Tetragonal; D. Pentagonal; E. Hexagonal; F. Round; G. Irregular; H. Egg-shaped.

Table 2. Frequency of different shapes of foramen magnum (FM) ( $\mathrm{n}=60)$

\begin{tabular}{lcc}
\hline Different shapes of FM & Number & Frequency (\%) \\
\hline Oval & 12 & 20 \\
Two semicircle & 10 & 16.67 \\
Tetragonal & 6 & 10 \\
Pentagonal & 5 & 8.33 \\
Hexagonal & 5 & 8.33 \\
Round & 4 & 6.67 \\
Irregular & 10 & 16.67 \\
Egg & 8 & 13.33 \\
Total & 60 & 100 \\
\hline
\end{tabular}

\section{DISCUSSION}

The foramen magnum is an important cranial structure with far-reaching implications for various fields of study. Most of the morphometric studies of the FM took into account the transverse and sagittal diameters as well as the area occupied by the foramen edge. Similarly, regarding the morphology of $F M$, the FM index (aspect ratio between sagittal and transverse diameters) has been largely the only measurable parameter used to evaluate the shape of the FM. This study is unique in that the FM index and dimensions are predicted from basic cranial index and measurements.

Rooppakhun et al. [20], in their study on computed tomography images of 91 Thai skulls, found the mean value of the cranial length of male skulls as $173.09 \pm 4.74 \mathrm{~mm}$, and the average value of $\mathrm{FM}$ length of the same skulls as $36.78 \pm 2.14 \mathrm{~mm}$. The ratio between these two lengths is 4.70 and it can be seen that it is within the confidence interval specified 
Table 3. Comparison of observed and predicted values with the literature

\begin{tabular}{|c|c|c|c|c|c|c|c|}
\hline \multirow[t]{2}{*}{ Studies } & \multirow[t]{2}{*}{ Gender } & \multirow[t]{2}{*}{$\mathbf{N}$} & \multirow{2}{*}{$\begin{array}{l}\text { Equation-1/ } \\
\text { /Equation-2 }\end{array}$} & \multicolumn{2}{|c|}{ Equation-3 (FMW) } & \multicolumn{2}{|c|}{ Equation-4 (FML) } \\
\hline & & & & $\begin{array}{l}\text { Prediction values } \\
\text { [mm] }\end{array}$ & $\begin{array}{c}\text { Observed values } \\
\text { [mm] }\end{array}$ & $\begin{array}{l}\text { Prediction values } \\
\text { [mm] }\end{array}$ & $\begin{array}{c}\text { Observed values } \\
\text { [mm] }\end{array}$ \\
\hline Rooppakhun et al. [20] & Male & 56 & 1.00 & 31.20 & 30.71 & 37.47 & 36.78 \\
\hline (Thai skulls) & Female & 35 & 0.99 & 30.48 & 28.90 & 35.75 & 34.29 \\
\hline Burdan et al. [4] & Male & 142 & 1.03 & 32.32 & 32.98 & 39.23 & 37.06 \\
\hline (Caucasian skulls) & Female & 171 & 0.93 & 31.22 & 30.95 & 37.36 & 35.47 \\
\hline Mahakkanukrauh et al. [17] & Male & 100 & 1.02 & 31.26 & 30.63 & 37.37 & 35.72 \\
\hline (Thai skulls) & Female & 100 & 1.02 & 30.02 & 28.89 & 35.50 & 33.44 \\
\hline Ramamoorthy et al. [19] & Male & 43 & 0.87 & 28.79 & 31.3 & 38.59 & 36.6 \\
\hline (Indian skulls) & Female & 27 & 0.89 & 27.71 & 30.7 & 36.90 & 36.5 \\
\hline Present study (Turkish skulls) & - & 60 & 1.01 & 28.01 & 28.14 & 35.16 & 35.81 \\
\hline
\end{tabular}

FMW — foramen magnum width; FML — foramen magnum length

in our study. In the same study, cranial width and FM width were found to be $144.13 \pm 5.45 \mathrm{~mm}$ and $30.71 \pm 2.05 \mathrm{~mm}$, respectively. The ratio between the widths is 4.69 and it is within the confidence interval in our study. In females, they reported the mean values of cranial and FM lengths as $165.15 \pm$ $\pm 6.61 \mathrm{~mm}$ and $34.29 \pm 2.35 \mathrm{~mm}$, respectively. In addition, Rooppakhun et al. [20] reported the mean values of cranial width and FM width of female skulls as $140.83 \pm 5.40 \mathrm{~mm}$ and $28.90 \pm 1.89 \mathrm{~mm}$, respectively. In females, the ratio between both cranial and FM lengths (4.81) and the ratio between cranial and FM widths (4.87) is very close to this range, although not within the confidence interval in our study. And according to the results of Rooppakhun et al. [20], the ratio of equation-1 (width index) and equation-2 (length index) to each other is approximately equal in both males and females (equation-1/equation-2 $=1.00$ for males, 0.99 for females) (Table 3 ). In this respect, our work is fully compatible with the study of Rooppakhun et al. [20].

The study of Burdan et al. [4] on computed tomography images of 313 Caucasian individuals reported the cranial length and width values of males as $181.22 \pm 7.53 \mathrm{~mm}$ and $149.33 \pm 6.57 \mathrm{~mm}$, respective$l y$, and $172.59 \pm 8.79 \mathrm{~mm}$ and $144.22 \pm 7.61 \mathrm{~mm}$ for females, respectively. In the same study, the length and width values of FM were reported as $37.06 \pm 3.07 \mathrm{~mm}$ and $32.98 \pm 2.78 \mathrm{~mm}$ in males, $35.47 \pm 2.60 \mathrm{~mm}$ and $30.95 \pm 2.71 \mathrm{~mm}$ in females, respectively. According to these results, it was determined that the ratio of cranial width to FM width in both males and females was within the confidence interval in our study (males: 4.53, females: 4.65). The ratio of cranial length to FM length was found very close to the confidence interval in both genders (male: 4.89, female: 4.86). According to the results of Burdan et al. [4], the ratio of equation-1 (width index) and equation-2 (length index) to each other was slightly lower in females, but the result obtained in males was consistent with our study. Our results were consistent with the results of males, while a little deviation in female (equation-1/equation-2 = 1.03 for males, 0.93 for females) (Table 3).

Mahakkanukrauh et al. [17], in their study on 200 Thai dried skulls (100 male, 100 female), reported cranial length and width values as $164.02 \pm 6.76 \mathrm{~mm}$, $138.68 \pm 5.33 \mathrm{~mm}$ in females and $172.64 \pm 6.23 \mathrm{~mm}$, $144.44 \pm 5.69 \mathrm{~mm}$ in males, respectively. Mahakkanukrauh et al. [17] reported the average length and width values of $\mathrm{FM}$ as $33.44 \pm 2.03 \mathrm{~mm}$ and $28.89 \pm 1.84 \mathrm{~mm}$ in females, $35.72 \pm 2.41 \mathrm{~mm}$ and $30.63 \pm 1.81 \mathrm{~mm}$ in males respectively. According to these reported measurements, it was determined that the ratio of cranial width to FM width in males was within the confidence interval in our study and very close to the confidence interval in females (male: 4.72, female: 4.80 ). The ratio of cranial length to FM length was very close to the confidence interval in both genders (male: 4.83, female: 4.90). And according to the results of Mahakkanukrauh et al. [17], the ratio of equation-1 (width index) and equation-2 (length index) to each other were equal in both males and females (equation-1/equation-2 = 1.02 for males, 
Table 4. Comparison of different shapes of foramen magnum (FM) with the previous reports

\begin{tabular}{lccccc}
\hline Different shapes of FM & Singh et al. [23] (n) & Chethan et al. [5] (n) & Govsa et al. [9] (n) & Sharma et al. [22] (n) & Current study (n) \\
\hline Oval & $33.3 \%(40)$ & $15.1 \%(8)$ & $7.93 \%(30)$ & $16 \%(8)$ & $20 \%(12)$ \\
Two semicircle & - & - & $23.28 \%(88)$ & - & $16.67 \%(10)$ \\
Tetragonal & $16.6 \%(20)$ & $18.9 \%(10)$ & $25.66 \%(97)$ & $12 \%(6)$ & $10 \%(6)$ \\
Pentagonal & $13.3 \%(16)$ & $3.8 \%(2)$ & $4.23 \%(16)$ & $8 \%(4)$ & $8.33 \%(5)$ \\
Hexagonal & $16.6 \%(20)$ & $5.61 \%(3)$ & $16.67 \%(63)$ & $8 \%(4)$ & $8.33 \%(5)$ \\
Round & $13.3 \%(16)$ & $22.6 \%(12)$ & $3.97 \%(15)$ & $22 \%(11)$ & $6.67 \%(4)$ \\
Pear & $6.6 \%(8)$ & - & - & - & - \\
Irregular & - & $15.1 \%(8)$ & $4.50 \%(17)$ & $18 \%(9)$ & $16.67 \%(10)$ \\
Egg & - & $18.9 \%(10)$ & $13.75 \%(52)$ & $16 \%(8)$ & $13.33 \%(8)$ \\
Total & $100 \%(120)$ & $100 \%(53)$ & $100 \%(352)$ & $100 \%(50)$ & $100 \%(60)$ \\
\hline
\end{tabular}

1,02 for females) (Table 3 ). In this respect, our work is fully compatible with the study of Mahakkanukrauh et al. [17].

The proportions obtained from the reported width values in the study of Ramamoorthy et al. [19] on 70 Indian adult skulls were lower than the current study and literature for both genders. Ramamoorthy et al. [19] reported cranial length and width values as $170.5 \pm 6.84 \mathrm{~mm}, 128 \pm 6.15 \mathrm{~mm}$ in females and $178.3 \pm 8.13 \mathrm{~mm}, 133 \pm 6.22 \mathrm{~mm}$ in males, respectively. They reported the average length and width values of $F M$ as $36.5 \pm 2.43 \mathrm{~mm}$ and $30.7 \pm 3.00 \mathrm{~mm}$ in females, $36.6 \pm 3.16 \mathrm{~mm}$ and $31.3 \pm 3.16 \mathrm{~mm}$ in males, respectively. According to these results, it was determined that the ratio of cranial width to FM width was found close to the confidence interval in both genders (male: 4.25 , female: 4.17 ). The ratio of cranial length to FM length was found within the confidence interval in females and very close confidence interval in males (males: 4.87, females: 4.67). To the results of Ramamoorthy et al. [19], the ratio of equation-1 (width index) and equation-2 (length index) to each other was slightly lower in both genders (equation-1/equation-2 $=0.87$ for males, 0.89 for females) (Table 3).

Some studies have focused on exploring external factors while FM takes its final form (the effect of sleeping position on the final form of FM in children under 5 years of age) [28]. Also some studies have evaluated the protrusion of occipital condyle and variations of the surrounding structures of the FM. Avcl et al. [2] reported that the occipital condyle protruded into the FM in $57 \%$ of the skulls examined.
Several researches have been made on the shape of the FM on the craniovertebral intersection. The most frequently observed FM type was reported as oval shaped by Singh et al. (33.3\%) [23], Avcl et al. (58\%) [2] and Henríquez-Pino et al. (87.3\%) [12], as round shaped by Chethan et al. (22.6\%) [5] and Sharma et al. (22\%) [22], as tetragonal shaped by Govsa et al. (25.66\%) [9]. In the present study, oval shape was the most common shape of the FM (20\%) (Fig. 2, Table 4).

\section{CONCLUSIONS}

In the present study, the ratio between the anteroposterior and transverse diameters of both FM and the cranium is 4.62 , indicating a magnificent harmony between cranial and subcranial structures. With this ratio, it is very easy to estimate the size of FM from basic cranial measurements.

Our research was conducted on 60 skulls; thus, it should be treated as a pilot study. We investigated the relationship between head length and width values and FM dimensions. We found that some data in the literature support this hypothesis. Besides, we calculated the rates we determined using the average values of the studies in the literature. However, similar studies should be carried out on material from various populations. Therefore, we suggest that the FM's anatomic and morphometric evaluation showed a significant difference between various parameters, so further comparative studies are required. Repeated anatomical observations deepen existing knowledge, help overcome the subjective aspect in the description made by individual researchers, and can be useful for practitioners [29]. 


\section{Acknowledgements}

The authors sincerely thank those whose bodies were used for anatomical research. Results from such research can potentially increase humankind's overall knowledge that can then improve patient care. Therefore, these donors and their families deserve our highest gratitude [15].

\section{Conflict of interest: None declared}

\section{REFERENCES}

1. Acer N, Sahin B, Ekinci N, et al. Relation between intracranial volume and the surface area of the foramen magnum. J Craniofac Surg. 2006; 17(2): 326-330, doi: 10.1097/00001665-200603000-00020, indexed in Pubmed: 16633182.

2. Avci E, Dagtekin A, Ozturk AH, et al. Anatomical variations of the foramen magnum, occipital condyle and jugular tubercle. Turk Neurosurg. 2011; 21(2): 181-190, doi: 10.5137/10195149.JTN.3838-10.1, indexed in Pubmed: 21534200.

3. Bernard S, Loukas M, Rizk E, et al. The human occipital bone: review and update on its embryology and molecular development. Childs Nerv Syst. 2015; 31(12): 2217-2223, doi: 10.1007/s00381-015-2870-8, indexed in Pubmed: 26280629.

4. Burdan F, Szumiło J, Walocha J, et al. Morphology of the foramen magnum in young Eastern European adults. Folia Morphol. 2012; 71(4): 205-216, indexed in Pubmed: 23197139.

5. Chethan P, Prakash KG, Murlimanju BV, et al. Morphological analysis and morphometry of the foramen magnum: an anatomical investigation. Turk Neurosurg. 2012; 22(4): 416-419, doi: 10.5137/1019-5149.JTN.4297-11.1, indexed in Pubmed: 22843456.

6. El-Atta HA, Abdel-Rahman R, El-Hawary G, et al. Sexual dimorphism of foramen magnum: An Egyptian study. Egypt J Foren Sci. 2020; 10(1), doi: 10.1186/s41935-019-0167-x.

7. Gapert R, Black S, Last J. Sex determination from the foramen magnum: discriminant function analysis in an eighteenth and nineteenth century British sample. Int J Legal Med. 2009; 123(1): 25-33, doi: 10.1007/s00414008-0256-0, indexed in Pubmed: 18553095.

8. George B, Lot G, Boissonnet H. Meningioma of the foramen magnum: a series of 40 cases. Surg Neurol. 1997; 47(4): 371-379, doi: 10.1016/s0090-3019(96)00204-2.

9. Govsa F, Ozer MA, Celik S, et al. Three-dimensional anatomic landmarks of the foramen magnum for the craniovertebral junction. J Craniofac Surg. 2011; 22(3): 1073-1076, doi: 10.1097/SCS.0b013e3182107610, indexed in Pubmed: 21586947.

10. Gruber P, Henneberg M, Böni T, et al. Variability of human foramen magnum size. Anat Rec (Hoboken). 2009; 292(11): 1713-1719, doi: 10.1002/ar.21005, indexed in Pubmed: 19777568.

11. Günay $Y$, Altinkök $M$. The value of the size of foramen magnum in sex determination. J Clin Forensic Med. 2000; 7(3): 147-149, doi: 10.1054/jcfm.2000.0430, indexed in Pubmed: 16083665 .

12. Henríquez-Pino J, Cricenti SV, Didio U. Morphometry of the foramen magnum and its relationship to skull types on Brazilian individuals. Rev Chil Anat. 1995; 13: 159-164.

13. Di leva A, Bruner E, Haider T, et al. Skull base embryology: a multidisciplinary review. Childs Nerv Syst. 2014; 30(6): 991-1000, doi: 10.1007/s00381-014-2411-x, indexed in Pubmed: 24740442.
14. Ilgun R, Ozkan ZE. Comparative study of some osteometric measurements of the neurocranium and splanchnocranium bones in Aksaray Malaklı and Kangal dogs. Firat University Veterinary Journal of Health Sciences. 2015; 29(3): 157-161.

15. Iwanaga J, Singh V, Ohtsuka A, et al. Acknowledging the use of human cadaveric tissues in research papers: Recommendations from anatomical journal editors. Clin Anat. 2021; 34(1): 2-4, doi: 10.1002/ca.23671, indexed in Pubmed: 32808702

16. Madadin M, Menezes RG, Al Saif HS, et al. Morphometric evaluation of the foramen magnum for sex determination: a study from Saudi Arabia. J Forensic Leg Med. 2017; 46: 66-71, doi: 10.1016/j.jflm.2017.01.001, indexed in Pubmed: 28157592.

17. Mahakkanukrauh P, Sinthubua A, Prasitwattanaseree S, et al. Craniometric study for sex determination in a Thai population. Anat Cell Biol. 2015; 48(4): 275-283, doi: 10.5115/ acb.2015.48.4.275, indexed in Pubmed: 26770879.

18. Manoel C, Prado FB, Caria PHF, et al. Morphometric analysis of the foramen magnum in human skulls of brazilian individuals: its relation to gender. Braz J Morphol Sci. 2009; 26(2): 104-108.

19. Ramamoorthy B, Pai MM, Prabhu LV, et al. Assessment of craniometric traits in South Indian dry skulls for sex determination. J Forensic Leg Med. 2016; 37: 8-14, doi: 10.1016/j. jflm.2015.10.001, indexed in Pubmed: 26519924.

20. Rooppakhun S, Surasith P, Vatanapatimakul N, et al. Craniometric study of Thai skull based on three-dimensional computed tomography (CT) data. J Med Assoc Thai. 2010; 93(1): 90-98, indexed in Pubmed: 20196417.

21. Samara O, Amarin J, Badran D, et al. Morphometric analysis of the foramen magnum. Int J Morphol. 2017; 35(4): 1270-1275, doi: 10.4067/s0717-95022017000401270.

22. Sharma S, Sharma A, Modi B, et al. Morphometric evaluation of the foramen magnum and variation in its shape and size: a study on human dried skull. Int J Anat Res. 2015; 3(3): 1399-1403, doi: 10.16965/ijar.2015.246.

23. Singh A, Agarwal $P$, Singh A. Morphological and morphometric study of foramen magnum in dry human skull and its clinical significance. Int J Anat Radiol Surg. 2019; 8(3): A010-A012, doi: 10.7860/IJARS/2019/41319:2488.

24. Spektor S, Anderson GJ, McMenomey SO, et al. Quantitative description of the far-lateral transcondylar transtubercular approach to the foramen magnum and clivus. J Neurosurg. 2000; 92(5): 824-831, doi: 10.3171/ jns.2000.92.5.0824, indexed in Pubmed: 10794297.

25. Teixeira WR. Sex identification utilizing the size of the foramen magnum. Am J Forensic Med Pathol. 1982; 3(3): 203-206, doi: 10.1097/00000433-198209000-00003, indexed in Pubmed: 7148772.

26. Ulutabanca $H$, Acer N, Küçük $A$, et al. Chiari type I malformation with high foramen magnum anomaly. Folia Morphol. 2015; 74(3): 402-406, doi: 10.5603/FM.2015.0059, indexed in Pubmed: 26339825.

27. Wanebo JE, Chicoine MR. Quantitative analysis of the transcondylar approach to the foramen magnum. Neurosurgery. 2001; 49(4): 934-41; discussion 941, doi: 10.1097/00006123-200110000-00027, indexed in Pubmed: 11564256.

28. Zdilla MJ, Russell ML, Bliss KN, et al. The size and shape of the foramen magnum in man. J Craniovertebr Junction Spine. 2017 ; 8(3): 205-221, doi: 10.4103/jcvjs.JCVJS 62 17, indexed in Pubmed: 29021672.

29. Żytkowski A, Tubbs R, Iwanaga J, et al. Anatomical normality and variability: Historical perspective and methodological considerations. Trans Res Anat. 2021; 23: 100105, doi: 10.1016/j.tria.2020.100105. 